\title{
Disparities of Implementation of National Test Based on Computer Between Western and Eastern Indonesia
}

\author{
Geovani Meiwanda \\ Faculty of Social and Political Science \\ Islamic University of Riau \\ Pekanbaru, Indonesia \\ geovanimeiwanda@gmail.com
}

\author{
Monalisa \\ Department of Government Science, UIR \\ Islamic University of Riau \\ Pekanbaru, Indonesia \\ fisipuirmonalisa@gmail.com
}

\begin{abstract}
E Government is an innovation of government in organizing government. This paper will explain about how currently the Government of Indonesia is running a system change of Education, which is the implementation of National test based on Computer (UNBK) through the Indonesian Ministry of Education and Culture. The implementation of National test based on Computer (UNBK) is expected to improve in terms of efficiency, quality, reliability, integrity and thrift of the implementation of the National Examination of the National budget. But the classic dilemma is still adjacent to the innovation made by the Government still there the Disparities that appeared on the implementation of National test based on Computer (UNBK) in 2017. Data show based on the division of Western Indonesia and Eastern Indonesia with three indicators of implementation of National test based on Computer (UNBK), Implementation in Other Schools and Non-National test based on Computer (UNBK) for the whole, National test based on Computer (UNBK) implemented in Western Indonesia $28.24 \%$ and in Eastern Indonesia 11.82\%. Non National test based on Computer (UNBK) in West Indonesia only $57.83 \%$ and in Eastern Indonesia $84.48 \%$. So this paper will give an in-depth analysis of why such a high Disparity occurs in the innovation of the implementation of the National test based on Computer (UNBK), as well as the factors that affect the disparity of the implementation of the National test based on Computer (UNBK). The research method used in this paper is literature study method, utilizing the source library as secondary data to obtain research data.
\end{abstract}

Keywords: Government; Innovation; Disparities; $E$ Government; UNBK

\section{INTRODUCTION}

The Government of Indonesia has made innovations by utilizing technology access to facilitate the various services provided to the community, This paper will show you the innovation made by Indonesian Government in the implementation of the National Exam held at elementary Schools, junior and senior high schools, known as the National Test based on Computer (UNBK). National test based on Computer (UNBK) itself has been recognized by the Government of Indonesia since 2014, held only at Indonesian-Singapore junior hight School and IndonesianMalaysian Junior hight School, the beginning of the implementation is a trial only in the two of this schools (1).

National test based on Computer (UNBK) is an innovation in the implementation of national examination by using technology with the server directly in each school, so no need to use stationery that will lead to the savings of the budget, the implementation of National test based on Computer (UNBK) can save the budget. The purpose of UNBK are efficiency, quality, reliability, and integrity. The implementation of UNBK uses a semi-online system that is sent from central server through the network to the local server (school), then the student exams are served by the local server (school) offline. Then the result of the test are sent back from the local server (school) to the central server online (upload).

In 2015, the pilot of National test based on Computer (UNBK) was conducted in 29 Provinces with 556 Schools. In 2016 the National test based on Computer (UNBK) was conducted in all provinces in Indonesia but only 4382 schools, and in 2017 implemented throughout Indonesia in 18,701 Schools, from the total number of Schools 97,645 from elementary, junior and high schools. Percentage of schools that perform National test based on Computer (UNBK) as a whole is $19.1 \%$ and in 2017 the implementation of National test based on Computer (UNBK) can save budget by $50 \%$ (2).

Indonesian Ministry of Education and Culture facilitates the implementation of National test based on Computer (UNBK) with the procurement of 4000 units of computers, and for some schools that lack the facilities can use schools that have complete facilities, this is because the implementation of National test based on Computer (UNBK) for elementary, junior and high schools is not simultaneously. This system is certainly pressing for all schools in Indonesia have a standard competence of the national exam evenly and reduce the occurrence of fraud. 
The implementation was not escaped from obstacles, plus it can not be denied there is an imbalance in education between the western and eastern Indonesia. Inequality from both those regions is also apparent in the implementation of National test based on Computer (UNBK), this following data of the implementation of National test based on Computer (UNBK) issued by the Indonesian Ministry of Education and Culture (3).

Table 1. Implementation of National test based on Computer in Indonesia 2017

\begin{tabular}{|l|l|c|c|c|}
\hline No. & Island & $\begin{array}{c}\text { UNBK } \\
(\%)\end{array}$ & $\begin{array}{c}\text { Implementatio } \\
\text { n outside of } \\
\text { School }(\%)\end{array}$ & $\begin{array}{c}\text { Non } \\
\text { UNBK } \\
(\%)\end{array}$ \\
\hline 1 & Sumatra & 18,01 & 9,10 & 72,88 \\
\hline 2 & Jawa & 48,10 & 14,31 & 37,58 \\
\hline 3 & $\begin{array}{l}\text { Bali, NTT, } \\
\text { dan NTB }\end{array}$ & 15,74 & 3,83 & 80,39 \\
\hline 4 & Kalimantan & 18,63 & 5,72 & 63,04 \\
\hline 5 & Sulawesi & 13,19 & 4,01 & 82,82 \\
\hline 6 & Maluku & 6,50 & 2,32 & 90,96 \\
\hline 7 & Papua & 11,85 & 4,56 & 83,58 \\
\hline
\end{tabular}

Source: Indonesian Ministry of Education and Culture, 2017 (processed by Author)

The data presented summarizes the implementation of the National test based on Computer (UNBK) per Island. Java Island with the highest percentage at $48.10 \%$ while the lowest is Maluku Island at $6.50 \%$. The number of the implementation of National test based on Computer (UNBK) show how far the level of implementation realization, where in Maluku still use manual system of implementation (stationery). There is an unevenness in the implementation, despite the efforts made to succeed the National test based on Computer (UNBK) with the allocation of 4000 Units Computer, and the implementation of National test based on Computer (UNBK) in other schools if there are schools that lack facilities, but the realization number still under standard (4).

Implementation of Non UNBK in the data of table 1, shows that overall almost above $50 \%$, only in Java island stand on lowest limited of Non UNBK at $37.58 \%$. This situation is in line if we facing to the educational situation in Indonesia right now, we can not denied that there are gaps of education sector between western and eastern of Indonesia. The accumulation of gap causes from year to year despite being covered with policies but still unable to answer the problem of disparity.

Equity is always been a problem that debated in various case of study between western and eastern Indonesia. Kaneko (2011) revealed that the reform in education sector was not separated from economic and social factors, problems that occur in Indonesia in the National test based on Computer is also not separated from those two things, economic and social disparities also have the same gap between western and eastern regions. Historically that disparity is not a thing that has existed for the past 5 or 10 years but it an accumulation of past economic policies. From the government of the old Order and the New Order development and economic activities centered on the Java and Sumatra island. This can be seen from the distribution of manufacturing industry, where more than $80 \%$ of Indonesia's manufacturing industry is located in Java. New Order's fiveyear development programs (PELITA), existing developments accumulate on the Java and Sumatra Island, such as the construction of Transportation, Education, Health, and Heavy Industries or Agricultural Industries, so that the Western Indonesia region, especially Java Island, experiencing rapid economic growth and development is not comparable with economic growth and development in other areas.

The purpose of this article is to analyze why the gaps occur in the implementation of National test based on Computer (UNBK) in the western and eastern Indonesia and what factors are affecting to this situation.

\section{SCOPE OF QUESTION}

Literature study method is used to assist authors in providing analysis. Utilization of library resources as secondary data to obtain research data. books, journals, and various reports relating to the disparity of the implementation of National test based on Computer (UNBK). The secondary data is reduced and synthesized according to the needs of the discussion.

a. Why so far away the disparities between Western and Eastern in implementing national test based on computer in Indonesia?

b. What factors Affecting the Disparities between Western and eastern Indonesia in implementing National test based on Computer?

\section{DISCUSSION}

Equity is a general concept of guarantees for the welfare of people in a country. The purpose of a country to provide prosperity for its people is explained into public policies. Equity itself has become a sensitive issue in Indonesia. Indonesia is an island Country separated by sea and strait, geographically the unity of this country is quite surprising. On the other hand the issue of equity brings its own sentiments to the people of Indonesia. The demands on equality is majority came from eastern Indonesia, where people felt that the development was concentrated only in Java and Sumatra. It is undeniable that Java is more developed than the other islands in Indonesia, even when compared with the mine-rich papua, Java is still higher in education implementation.

Along with that, Indonesia's educational growth rate is quite high these days despite the change of education structure and high level of economic growth only occurs at 
national level, while at the regional level not all regions feel the benefit from the high national growth. Because there has been a very high disparity, such as Java with outside Java or between Western Indonesia and Eastern Indonesia, this case can be seen from innovation of National test based on Computer (UNBK) conducted in 2017 (see table 1).

In contrast to Java or Sumatra, the problems faced in the development of eastern Indonesia are relatively left behind, among other reasons are: (1) the limited access of transportation connecting the underdeveloped regions with relatively more developed regions due to the shape of eastern Indonesia which is archipelago like Maluku and Nusa Tenggara and the mountains of Papua; (2) density when viewed from the social aspect. Linked to the implementation of UNBK itself there are several problems that will be studied based on western and eastern region, following of table implementation of UNBK in Indonesia based on region western and eastern.

Tabel 2. implementation of National test based on Computer Based on the Regional Division 2017

\begin{tabular}{|c|c|c|c|c|}
\hline No. & Region & $\begin{array}{l}\text { UNBK } \\
(\%)\end{array}$ & $\begin{array}{l}\text { Implementation } \\
\text { outside of } \\
\text { School (\%) }\end{array}$ & $\begin{array}{l}\text { Non } \\
\text { UNBK } \\
(\%)\end{array}$ \\
\hline 1 & $\begin{array}{c}\text { Western } \\
\text { Indonesia } \\
\text { (IBB) }\end{array}$ & 28,24 & 9,72 & 57,83 \\
\hline 2 & $\begin{array}{c}\text { Eastern } \\
\text { Indonesia } \\
\text { (ITB) }\end{array}$ & 11,82 & 3,68 & 84,48 \\
\hline
\end{tabular}

Source: Indonesian Ministry of Education and Culture, 2017 (processed by Author)

The table above can be analyzed that basically $57.83 \%$ in the western region has not implemented UNBK, and for eastern region $84.48 \%$ who have not implemented UNBK. If return to the table 1 data shows that the perfection of the implementation of this UNBK performed well on the Java island with the highest implementation ranking in the D.I. Yogyakarta province. UNBK is conducted based on instruction in Government Regulation No. 5 of 2015, which is the policy of implementation of National test based on Computer (Computer Based Test). The target of improvement effort of this policy are student, teacher, study method, indicator of learning, content of lesson, media and evaluation (5).

Obstacles that arise in the implementation of UNBK in the eastern region can not be separated from the Gap problem in general, such as computers, electrical power and the internet. The Internet is a major problem when the Government is ready to implement the National Examination Policy by cooperating with technology, it must be ready also with the availability of infrastructure, electricity and internet in its implementation in the regions in cooperation with the Office of Communication and Information in each region, as well as ensuring that the schools are ready as organizers and consider schools that are far away enough for those who conduct exams outside school.

The education policy that holds technology hopefully increasing and emphasizes the improvement the capability to the students as well as teachers because of its direction is on the readiness when implementing. Output of this policy is certainly to improve the quality of Education in Indonesia. Education is the main goal to bringing positive experiences to people's life, easy job to come by and including the side effects of mental health (Borland 2002; Card 2001; Wolfe and Haveman 2001). So that when educational gap is allowed to drag on, despite the create of a new policy, but not being able to solve the main root of the disparity itself it will not be the great output of the policy. Infrastructure, electrical power and internet are the main allocations when using a computer based test system.

The number of disparity between the western and eastern region of Indonesia are not only in the implementation of UNBK but also in allover of Education, the problem of infrastructure are the main thing that must be met when creating a policy. According to World Bank Report ,infrastructure is divided into 3 groups (World Bank, 1994: 12):

1. Infrastructure Economy, is a physical asset that provides services and is used in final production and consumption including public utilities (telecommunication, drinking water, sanitation and gas), public works (dams, irrigation channels and drainage) as well as the transport sector (roads, railways, ports and airports)

2. Social Infrastructure is an asset that supports community health and skills including education (schools and libraries), health (hospitals, health centers) as well as for recreation (parks, museums and others).

3. Infrastructure Administration / Institution, including law enforcement, administrative control and coordination and culture.

UNBK is a good innovation with main goal is achieving aspects of improving efficiency, quality, reliability, integrity and savings. Infrastructure aspect must remain the main focus with the procurement of 4000 units computer still can not answer the needs, plus electricity and also the internet. Of the overall approximately $80 \%$ of Eastern Indonesia has not implemented UNBK, it is constrained from Geographic area where the distance is quite far apart when doing UNBK outside of school. Electrical power in the eastern region with the lowest installed capacity of 187.82 and with a peak load of 389.95 (PLN, 12) and the last, internet facility is less evenly distributed. 
UNBK in the western region was categorized as better implementation, the success of UNBK is almost in all areas of Java Island specifically, and it is not separated from the completeness of existing infrastructure on the Java island to facilitate the implementation of UNBK. Apergis and Payne (2009) and Guttormsen (2004) argue that the growth of electricity will affect many sectors, and the electricity in the western region especially in Java is particularly suited in line with the economic growth and quality of education which is Java is ranked the highest (6).

\section{CONCLUSION}

The issue of disparity in the implementation of UNBK between western Indonesia and eastern Indonesia is inseparable from the uneven development pattern since independence. Development centered in the western region, especially in Java and making the outer Java areas which is the rich as the support of development for Java itself, leaving the outer Java islands suffering from this economic and political centralization.

Disparities that occur in the implementation of UNBK between western and eastern Indonesia, can not be separated from the limitations in other areas, meaning is when assessing the problem of gaps is not a problem in its UNBK policy but in the field of education itself and direction magnitude is a disparity in the economic and social when we analyze why ultimately the unbalanced infrastructure becomes the benchmark of UNBK's success in Indonesia, therefore the inaccessibility of infrastructure problems in Papua, as well as other isolated areas in Indonesia, becomes the most superficial issue of this disparities.

The emphasis on this situation is how the collaboration should be generated, and mandatory when it has entered the era of digital government then the state must be ready to prepare all forms of support for success, including the solving of the main problem which is the gap between western and eastern Indonesia. in principle the policy in carrying out UNBK is in line with Nawacita program of Joko Widodo President of Indonesia with emphasis on infrastructure development, human resources and economy, but the emphasizing is on how this education policy can be perceived evenly and the emphasizing the main effort in the equitable distribution of infrastructure supporting to the implementation of UNBK.

\section{REFERENCES}

[1] Apergis, N. and J .E. Payne. 2009. The emissions, energy consumption, and growth nexus: Evidence from the commonwealth of independent states. Energy Policy 38(1): 650-655

[2] Biddle, Nicholas., Yap, Mandy. 2010. Demographic and Socioeconomic Outcomes Across the Indigenous Australian
Lifecourse. ANU Press: Canberra

[3] Guttormsen, A.G. 2004. Causality between Energy Consumption and Economic Growth. Department of Economics and Resource Management, Agriculture University of Norway: Norway.

[4] Kaneko, Motohisa. 2011. Higher Education Policies and Development: Approach to funding higher education in Japan. ANU Press: Canberra.

[5] The World Bank. 1994. World Bank Development Report 1994 Infrastructure For Development. New York. Oxford University.

[6] Wolfe, Barbara L., Haveman, Robert H. 2001. Schooling and Economic Well-Being: The Role of Nonmarket Effects. The Journal of Human Resources, Volume 19, Issues 3, 377-407 